From the University of California Irvine Chao Family Comprehensive Cancer Center, Orange; Women's and Children's Hospital, University of Southern California, Los Angeles, CA; Gynecologic Oncology Group Statistical and Data Center, Roswell Park Cancer Institute; Department of Biostatistics, University at Buffalo, Buffalo, NY; University of Washington, Fred Hutchinson Cancer Research Center, Seattle, WA; and University of lowa, lowa City, IA.

Submitted July 14, 2008; accepted September 23, 2008; published online ahead of print at www.jco.org on January 12, 2009.

Supported by Grant No. CA 27469 to the Gynecologic Oncology Group Administrative Office and Grant No. CA 37517 to the Gynecologic Oncology Group Statistical and Data Center from the National Cancer Institute $(\mathrm{NCl})$ and Grant No. CA 87558 (K-23 grant; B.J.M.) from the National Institutes of Health. The clinical trial upon which this article is based was sponsored by the Cancer Therapy Evaluation Program of the $\mathrm{NCl}$, under the Collaborative Research and Development Agreement for bevacizumab between $\mathrm{NCl}$ and Genentech Inc.

Presented in part at the 39th Annual Meeting of the Society of Gynecologic Oncologists, March 9-12, 2008, Tampa, FL.

Authors' disclosures of potential conflicts of interest and author contributions are found at the end of this article.

Corresponding author: Bradley J. Monk $M D$, University of California, Irvine

Medical Center, Bldg 56, Room 262, 101 The City Dr, Orange, CA 92868: e-mail: bjmonk@uci.edu.

The Acknowledgment is included in the full-text version of this article, available online at www.jco.org. It is not included in the PDF version (via Adobe $®$ Reader $\circledast$ )

(C) 2009 by American Society of Clinical Oncology

0732-183X/09/2707-1069/\$20.00

DOI: $10.1200 / J C O .2008 .18 .9043$

\section{Phase II Trial of Bevacizumab in the Treatment of Persistent or Recurrent Squamous Cell Carcinoma of the Cervix: A Gynecologic Oncology Group Study}

\title{
$\begin{array}{llllllll}A & B & S & T & R & A & C & T\end{array}$
}

\section{Purpose}

Vascular endothelial growth factor is a key promoter of tumor progression in cervical carcinoma. The Gynecologic Oncology Group (GOG) conducted a phase II trial to assess the efficacy and tolerability of bevacizumab, a recombinant humanized anti-vascular endothelial growth factor monoclonal antibody.

\section{Patients and Methods}

Eligible patients had recurrent cervical cancer, measurable disease, and GOG performance status $\leq 2$. Treatment consisted of bevacizumab $15 \mathrm{mg} / \mathrm{kg}$ intravenously every 21 days until disease progression or prohibitive toxicity. Primary end points were progression-free survival (PFS) at 6 months and toxicity.

\section{Results}

Forty-six patients were enrolled (median age, 46 years); 38 patients $(82.6 \%)$ received prior radiation as well as either one ( $n=34,73.9 \%)$ or two $(n=12,26.1 \%)$ prior cytotoxic regimens for recurrent disease. Grade 3 or 4 adverse events at least possibly related to bevacizumab included hypertension ( $n=7)$, thrombo-embolism ( $n=5)$, GI $(n=4)$, anemia ( $n=2)$, other cardiovascular ( $n=2)$, vaginal bleeding $(n=1)$, neutropenia $(n=1)$, and fistula $(n=1)$. One grade 5 infection was observed. Eleven patients (23.9\%; two-sided $90 \% \mathrm{Cl}, 14 \%$ to $37 \%$ ) survived progression free for at least 6 months, and five patients (10.9\%; two-sided $90 \% \mathrm{Cl}, 4 \%$ to $22 \%$ ) had partial responses. The median response duration was 6.21 months (range, 2.83 to 8.28 months). The median PFS and overall survival times were 3.40 months $(95 \% \mathrm{Cl}, 2.53$ to 4.53 months) and 7.29 months $(95 \% \mathrm{Cl}, 6.11$ to 10.41 months), respectively. This compared favorably with historical phase II GOG trials in this setting.

\section{Conclusion}

Bevacizumab seems to be well tolerated and active in the second-and third-line treatment of patients with recurrent cervical cancer and merits phase III investigation.

\section{J Clin Oncol 27:1069-1074. (C) 2009 by American Society of Clinical Oncology}

\section{INTRODUCTION}

Although likely an underestimate, Parkin et $\mathrm{al}^{1}$ reported that cervical cancer affected 493,243 women worldwide in 2002, thereby making it the second most common female cancer. In addition, it is the third most common cause of female cancer mortality annually with 273,505 deaths reported. In developed countries such as the United States, cervical cancer incidence and mortality rates have declined approximately $75 \%$ over the last three decades. Still, the disease remains a serious American health threat with an estimated incidence and mortality of 11,150 and 3,670 in 2007, respectively. ${ }^{2}$

Cervical cancer is preventable and is usually curable if detected early. ${ }^{3}$ Treatment paradigms in the primary management of cervical cancer are well established with early lesions generally being treated surgically and locally advanced lesions being managed with concurrent cisplatin chemotherapy and pelvic radiation. ${ }^{4,5}$ Metastatic disease or recurrent lesions not amenable to radical local excision or regional radiation are treated with palliative chemotherapy. The Gynecologic Oncology Group (GOG) has reported on seven randomized phase III trials in this setting, with only one regimen being superior to single-agent cisplatin administered intravenously at $50 \mathrm{mg} / \mathrm{m}^{2}$ every 3 weeks. ${ }^{6}$ This trial showed that adding topotecan $0.75 \mathrm{mg} / \mathrm{m}^{2}$ on the first 3 days of a 21-day cycle to cisplatin prolonged the median survival time by 2.9 months (from 6.5 to 9.4 months; $P=.017)$ with an unadjusted relative risk estimate 
for survival of 0.76 (95\% CI, 0.593 to $0.979 ; P=.017$, one tailed) compared with cisplatin alone. ${ }^{7}$ Although the cisplatin-topotecan doublet is associated with more bone marrow suppression compared with cisplatin alone, there was no decrement in quality of life associated with the combination. ${ }^{8}$

Prognostic factors shown to be important in predicting outcome in the treatment of recurrent cervical cancer include the interval from initial therapy to the time of recurrence, number of prior chemotherapy regimens including prior radiotherapy-sensitizing cisplatin, site of recurrence (with lesions in an irradiated field having a lower chance of response), and worse baseline quality of life. ${ }^{7-10}$

The GOG is currently performing its eighth randomized phase III clinical trial (Protocol 204) in recurrent cervical cancer, and this trial is designed to determine the optimal cisplatin doublet. This fourarm study evaluates four cisplatin combinations including topotecan, paclitaxel, vinorelbine, and gemcitabine. This definitive trial will clarify which platinum doublet is optimal in this setting, making further significant advances in cytotoxic therapy in recurrent cervical cancer even more difficult.

Clearly, more effective agents are needed to treat women with advanced and recurrent cervical carcinoma. With angiogenesis being a pivotal pathway in cervical carcinogenesis and progression, targeting this pathway is rational. Several authors have reported a strong association with vascular endothelial growth factor expression in cervical cancer and poor prognosis. ${ }^{11,12}$ Bevacizumab is a humanized antivascular growth factor (vascular endothelial growth factor) monoclonal antibody that has shown activity in many solid tumors. ${ }^{13}$ Thus, the GOG conducted a phase II trial of single-agent bevacizumab in patients with persistent or recurrent cervical cancer. At the time this study was designed (circa 2001), bevacizumab was not expected to have a significant, cytotoxic effect on existing tumor cells, so the drug was evaluated as a cytostatic agent. For this reason, the primary end points of this study were the proportion of patients with progressionfree survival (PFS) for at least 6 months and the frequency and severity of adverse events. The secondary objectives were to estimate the probability of clinical response, the distribution of overall survival (OS), the distribution of PFS, and the impact of potential prognostic factors on PFS or OS.

\section{PATIENTS AND METHODS}

Eligibility criteria included patients with persistent or recurrent squamous cell carcinoma of the cervix (including adenosquamous tumors) that was measurable by Response Evaluation Criteria in Solid Tumors; ${ }^{14}$ one or two prior cytotoxic regimens, not including prior cisplatin-based chemotherapy concomitantly administered with primary pelvic radiation; GOG performance status (PS) of 0 or 1 , with PS level 2 allowed in patients having received only one prior cytotoxic regimen; and adequate hematologic (absolute neutrophil count $\geq 1,500 / \mu \mathrm{L}$ and platelets $\geq 100,000 / \mu \mathrm{L}$ ), renal (serum creatinine $\leq 1.5 \times$ the institutional upper limit of normal [ULN]; if higher, then creatinine clearance $>60 \mathrm{~mL} / \mathrm{min}$ was required), hepatic (serum bilirubin $\leq 1.5 \times$ ULN, and both AST and alkaline phosphatase $\leq 2.5 \times \mathrm{ULN}$ ), and coagulation (prothrombin time such that international normalized ratio is $\leq 1.5$ or between 2.0 and 3.0 for patients on stable doses of therapeutic anticoagulants and partial thromboplastin time $<1.2 \times$ control) laboratory values. Documentation of tumor type was confirmed by central review by the GOG Pathology Committee.

Patients with nonsquamous tumors (eg, adenocarcinomas), other malignancies evident within 5 years, prior noncytotoxic therapy for management of recurrent or persistent cervical cancer, nonhealing wounds, infection requiring antibiotics, active bleeding, coagulopathy, or CNS disease (primary brain tumor history, brain metastases, uncontrolled seizure disorder, or cerebrovascular accident within 6 months) were ineligible. Patients were also excluded for significant cardiovascular disease (uncontrolled hypertension, myocardial infarction or angina within 6 months, New York Heart Association $\geq$ grade 2 congestive heart failure, or cardiac arrhythmia requiring medication), modified Fontaine $\geq$ grade 2 peripheral vascular disease or claudication within 6 months, $\geq 1.0$ g of proteinuria per 24 hours, pregnancy or nursing, prior therapy with bevacizumab, or major surgical procedures within 28 days or anticipated while on study. ${ }^{15}$ The study received local institutional review board approval at participating institutions, and all patients gave informed consent according to institutional and federal guidelines before enrollment.

Enrolled patients were to receive bevacizumab $15 \mathrm{mg} / \mathrm{kg}$ intravenously every 21 days with no dose modification except in cases when there was at least a $10 \%$ change in body weight. This dose and schedule of bevacizumab were selected because of the average 21-day half-life of the drug when administered systemically, the dose density similar to that used in active phase II trials in other disease sites, and the potential for combining bevacizumab with standard primary cytotoxic therapy regimens in future phase III trials for patients with cervical cancer. ${ }^{13}$

Toxicity was monitored with history, physical examination, and laboratory assessment before each treatment cycle, with adverse events defined and graded according to National Cancer Institute Common Toxicity Criteria version 2.0. ${ }^{16}$ Bevacizumab was to be held for grade 3 nonhematologic toxicity for a maximum of 3 weeks to allow resolution to grade 1 or less. Treatment was discontinued for any grade 4 nonhematologic toxicity.

Activity of bevacizumab was assessed according to Response Evaluation Criteria in Solid Tumors either by palpation before each cycle for peripheral lesions or by computed tomography or magnetic resonance imaging at baseline and before every other cycle for the last 29 patients after amending the protocol (the first 17 eligible and assessable patients were evaluated before cycles $5,7,9$, and so on, skipping the evaluation before cycle 3) for the measurement of target lesions, the classification of clinical response, and the determination of disease progression. ${ }^{14}$ Therapy was discontinued for disease progression, unacceptable toxicity, receipt of other anticancer therapy, or voluntary withdrawal.

The level of activity that would be considered interesting for future phase III studies was determined from an evaluation of historical control data involving six GOG trials performed in similar patients to those enrolled onto the current study (Table 1). ${ }^{17-22}$ Because cytostatic agents are often better tolerated than cytotoxic agents, the purpose of the protocol was to screen agents for any activity greater than a limit that is considered clinically uninteresting. This limit was established with the help of previously reported studies. The historical phase II trials included the use of some agents such as cisplatin, topotecan, and gemcitabine, which have been studied in GOG phase III trials in recurrent cervical cancer, as well as other agents with minimal to modest activity such as isotretinoin plus interferon alfa, altretamine, and etoposide. ${ }^{17-22}$ The latter agents were selected for comparison and used to help establish that 10\% PFS at 6 months was uninteresting.

Bevacizumab was to be considered interesting if eight or more patients survived (progression free) for $\geq 6$ months, assuming an accrual of 46 to 51 patients. Specifically, using a two-stage design, the targeted sample size for the first stage of accrual was 22 eligible and assessable patients but was permitted to range from 19 to 26 patients for administrative reasons. If there were more than two of 19 to 25 patients or more than three of 26 patients alive and progression free for at least 6 months and medical judgment indicated, accrual to the second stage of the trial was to be initiated. Otherwise, the treatment regimen was to be classified as clinically uninteresting without any additional accrual. If the study advanced to the second stage, then an overall sample size of 47 eligible and assessable patients was targeted but was permitted to range from 44 to 51 patients. If there were no more than six of 44 to 45 patients or no more than seven of 
Table 1. Historical Database Used to Help Assess the Activity of Bevacizumab in GOG Protocol 227-C Among Women With Recurrent Cervical Cancer After Experiencing Treatment Failure With One or Two Cytotoxic Regimens (not including chemotherapy with primary radiation)

\begin{tabular}{|c|c|c|c|c|c|c|c|}
\hline \multirow{2}{*}{$\begin{array}{l}\text { Protocol Study } \\
\text { Section }\end{array}$} & \multirow[b]{2}{*}{ Agents Studied } & \multirow{2}{*}{$\begin{array}{l}\text { No. of Eligible and } \\
\text { Assessable Patients }\end{array}$} & \multicolumn{2}{|c|}{$\begin{array}{c}\text { Probability of PFS } \\
>6 \text { Months* }\end{array}$} & \multirow{2}{*}{$\begin{array}{l}\text { Median Survival } \\
\text { (months) }\end{array}$} & \multicolumn{2}{|c|}{ Response } \\
\hline & & & Estimate & SE & & No. of Patients & $\%$ \\
\hline $127 \mathrm{~B}^{17}$ & Isotretinoin and interferon alfa & 34 & 0.06 & 0.04 & 3.9 & 1 & 3 \\
\hline $127 C^{18}$ & Cisplatin and pentoxifylline & 44 & 0.20 & 0.06 & 6.0 & 4 & 9 \\
\hline $127 D^{19}$ & Altretamine & 29 & 0.03 & 0.03 & 4.6 & 0 & 0 \\
\hline $127 \mathrm{~F}^{20}$ & Topotecan & 40 & 0.15 & 0.06 & 6.6 & 5 & 12 \\
\hline $127 \mathrm{H}^{21}$ & Etoposide & 24 & 0.12 & 0.07 & 3.7 & 2 & 8 \\
\hline $127 K^{22}$ & Gemcitabine & 25 & 0.04 & 0.04 & 4.8 & 2 & 8 \\
\hline 227C (current report) & Bevacizumab & 46 & 0.24 & 0.06 & 7.3 & 5 & 11 \\
\hline
\end{tabular}

NOTE. There are no study sections labeled $A, E, G, I, J$, or $O$.

Abbreviations: GOG, Gynecologic Oncology Group; PFS, progression-free survival.

*Product limit estimate of the cumulative probability of surviving progression-free $>6$ months.

46 to 51 patients who were alive and progression free after 6 months, then the regimen was to be considered clinically uninteresting. For a true probability of being alive and progression free after 6 months of $25 \%$, the average probability of correctly classifying the treatment as active was $90 \%$; whereas for a true probability of $10 \%$, the average probability of designating the treatment as active (a false-positive misclassification) was $10 \%$, and the average probability of stopping after completing the first stage of accrual was $64 \% .^{23}$ The distribution of PFS and OS for patients on this study was described using Kaplan-Meier plots and median estimates. Prognostic factors were evaluated with Cox proportional hazards models using end points for PFS and OS. The factors assessed included age (in years), exposure to prior radiation therapy, one versus two prior chemotherapy regimens, African American versus other race, performance status of 0 or worse, and location of target tumor within or outside the zone of prior radiation. We also examined prior cisplatin use as a sensitizer to radiation; because the amount of missing data in this analysis was high ( 15 observations, corresponding to approximately $33 \%$ of the patients), this analysis was conducted separately. All of the analyses, regardless of the level of missing data, were considered exploratory, and given the small sample size and the number of relationships examined, all results were considered hypothesis generating rather than hypothesis testing. The reported $P$ values were considered indicators of possible association but were not meant to be interpreted as statistically significant in the traditional sense.

\section{RESULTS}

\section{Patient Characteristics}

From April 2002 through November 2006, 50 patients were enrolled, of whom four were excluded (one for wrong histologic cell type, one for wrong primary tumor site, one for inappropriate prior therapy, and one for no documentation of treatment). Thus, the study sample consisted of 46 patients with a median age of 46 years (range, 29 to 62 years); 32 patients $(69.6 \%)$ were white, and 22 patients $(47.8 \%)$ had a GOG performance status of 0 . Disease characteristics of the study group are listed in Table 2.

A total of 254 cycles of bevacizumab were administered, with a median of four cycles per patient. As of April 2008, 44 patients have discontinued therapy, 36 for disease progression, four for toxicity (all as a result of thrombosis), one for bowel obstruction, one for refusal of further therapy, and one for thrombosis not related to treatment. One patient died on treatment of a grade 5 infection possibly attributed to therapy. Thirty-seven patients died of disease progression, and one patient died from disease and treatment (the grade 5 infection noted earlier). Eight patients $(17.4 \%)$ are alive; three of these patients are alive without progression with two remaining on treatment.

\begin{tabular}{|c|c|c|}
\hline Characteristic & No. of Patients & $\%$ \\
\hline \multicolumn{3}{|l|}{ Age, years } \\
\hline 20-29 & 1 & 2.2 \\
\hline $30-39$ & 11 & 23.9 \\
\hline $40-49$ & 17 & 37.0 \\
\hline $50-59$ & 12 & 26.1 \\
\hline 60-69 & 5 & 10.9 \\
\hline \multicolumn{3}{|l|}{ Race/ethnicity } \\
\hline Asian & 3 & 6.5 \\
\hline African American & 4 & 8.7 \\
\hline Hispanic & 6 & 13.0 \\
\hline American Indian & 1 & 2.2 \\
\hline White & 32 & 69.6 \\
\hline \multicolumn{3}{|l|}{ Performance status } \\
\hline 0 & 22 & 47.8 \\
\hline 1 & 23 & 50.0 \\
\hline 2 & 1 & 2.2 \\
\hline \multicolumn{3}{|l|}{ Cell type } \\
\hline Adenosquamous & 3 & 6.5 \\
\hline Squamous cell carcinoma & 43 & 93.5 \\
\hline \multicolumn{3}{|l|}{ Grade } \\
\hline 1 (well differentiated) & 3 & 6.5 \\
\hline 2 (moderately differentiated) & 25 & 54.3 \\
\hline 3 (poorly differentiated) & 18 & 39.1 \\
\hline \multicolumn{3}{|l|}{ Prior chemotherapy* } \\
\hline 1 prior regimen & 34 & 73.9 \\
\hline 2 prior regimens & 12 & 26.1 \\
\hline \multicolumn{3}{|l|}{ Prior radiation } \\
\hline No & 8 & 17.4 \\
\hline Yes & 38 & 82.6 \\
\hline \multicolumn{3}{|l|}{ Prior hysterectomy } \\
\hline No & 20 & 43.5 \\
\hline Yes & 26 & 56.5 \\
\hline
\end{tabular}

${ }^{*}$ Chemotherapy was not administered in conjunction with primary radiation because a radiotherapy sensitizer is not counted under prior chemotherapy. 


\section{Adverse Events}

As shown in Table 3, safety of bevacizumab in all 46 patients was analyzed descriptively; events listed had been reported as at least possibly related to study drug. There were eight events related to grade 3 hematologic toxicity (no grade 4). Five patients experienced a deep venous thrombosis, one with pulmonary embolus. There were no cases of arterial thrombosis. There was one episode of grade 4 vaginal bleeding and one grade 4 urinary fistula. From the standpoint of other nonhematologic toxicities, bevacizumab was well tolerated in this cohort. Other notable grade 3 and grade 4 events included hypertension (seven grade 3 and zero grade 4 events), other cardiovascular (two grade 3 and zero grade 4 events), GI (three grade 3 events and one grade 4 event), and genitourinary/renal (two grade 3 events and one grade 4 fistula). Finally, there was no grade 4 proteinuria or hypertension requiring discontinuation of therapy, although there was one grade 5 infection as mentioned earlier.

\section{Activity of Bevacizumab}

The activity of bevacizumab was analyzed in 46 patients. Eleven patients (23.9\%; two-sided 90\% CI adjusted for the interim decision rule [Clopper and Pearson ${ }^{24}$ ], $14.0 \%$ to $36.5 \%$ ) survived progression free for at least 6 months, and five patients (10.9\%; two-sided exact binomial $90 \%$ CI, $4.4 \%$ to $21.5 \%$ ) experienced partial responses. The median response duration was 6.21 months (range, 2.83 to 8.28 months). The median PFS and OS times for all patients were 3.40 months ( $95 \%$ CI, 2.53 to 4.53 months) and 7.29 months (95\% CI, 6.11 to 10.41 months), respectively. The graph of the Kaplan-Meier estimates of PFS and OS for the study population is shown in Figure 1.

\begin{tabular}{|c|c|c|c|c|c|c|}
\hline \multirow[b]{2}{*}{ Adverse Effect } & \multicolumn{5}{|c|}{ Grade (No. of patients) } & \multirow{2}{*}{$\begin{array}{l}\text { Total No. } \\
\text { of Patients }\end{array}$} \\
\hline & 0 & 1 & 2 & 3 & 4 & \\
\hline Leukopenia & 39 & 3 & 3 & 1 & 0 & 46 \\
\hline Thrombocytopenia & 43 & 3 & 0 & 0 & 0 & 46 \\
\hline Neutropenia & 42 & 2 & 1 & 1 & 0 & 46 \\
\hline Anemia & 26 & 8 & 10 & 2 & 0 & 46 \\
\hline Other hematologic & 41 & 1 & 0 & 4 & 0 & 46 \\
\hline Allergy & 45 & 1 & 0 & 0 & 0 & 46 \\
\hline Hypertension & 33 & 4 & 2 & 7 & 0 & 46 \\
\hline Thrombosis embolism & 41 & 0 & 0 & 4 & 1 & 46 \\
\hline Other cardiovascular & 34 & 8 & 2 & 2 & 0 & 46 \\
\hline Coagulation & 43 & 2 & 0 & 1 & 0 & 46 \\
\hline Constitutional & 22 & 16 & 6 & 2 & 0 & 46 \\
\hline Dermatologic & 36 & 5 & 5 & 0 & 0 & 46 \\
\hline $\mathrm{Gl}$ & 25 & 7 & 10 & 3 & 1 & 46 \\
\hline Genitourinary/renal & 34 & 6 & 3 & 2 & 1 & 46 \\
\hline Hemorrhage & 38 & 5 & 2 & 0 & 1 & 46 \\
\hline Hepatic & 35 & 11 & 0 & 0 & 0 & 46 \\
\hline Infection* & 40 & 0 & 3 & 2 & 1 & 46 \\
\hline Metabolic & 29 & 16 & 0 & 1 & 0 & 46 \\
\hline Neuropathy sensor & 41 & 3 & 2 & 0 & 0 & 46 \\
\hline Other neurologic & 41 & 2 & 3 & 0 & 0 & 46 \\
\hline Pain & 27 & 8 & 5 & 6 & 0 & 46 \\
\hline Pulmonary & 38 & 1 & 5 & 2 & 0 & 46 \\
\hline \multicolumn{7}{|c|}{$\begin{array}{l}\text { NOTE. The maximum severity of each adverse event per patient, graded } \\
\text { according to Common Toxicity Criteria version } 2.0 \text {, is reported. Events were } \\
\text { restricted to those reported as at least possibly related to study drug. } \\
\text { "Listed grade } 4 \text { infection is actually grade } 5 \text {. }\end{array}$} \\
\hline
\end{tabular}

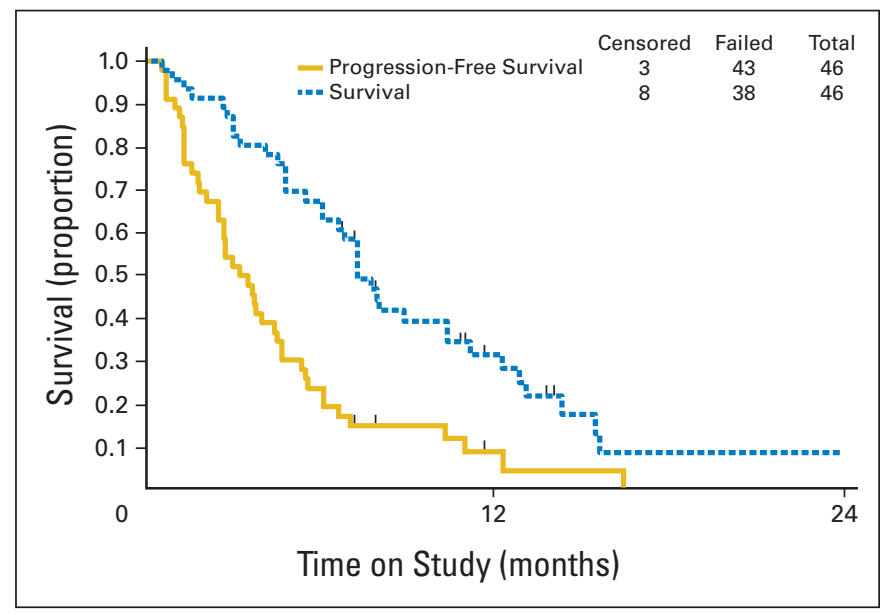

Fig 1. Overall survival and progression-free survival Kaplan-Meier plots for the 46 patients in the study sample.

The PFS in this study is shown with the PFS of studies in the GOG historical database in Figure 2.

\section{Exploratory Analysis of Patient Characteristics and PFS and Survival During Treatment With Bevacizumab}

Results of the exploratory analyses are reported in Table 4. Race and performance status may be associated with PFS and OS. African Americans seemed to be younger (mean age of 35 years $v 48$ years for other races), had a worse PS, and had less prior chemotherapy before coming onto this study. This may explain some of the results seen jointly. A separate analysis of the potential effects of prior cisplatin as a radiation sensitizer showed no significant results with regard to PFS or OS.

\section{DISCUSSION}

When detected early, cervical cancer is almost always controlled with regional therapy. However, when women with metastatic

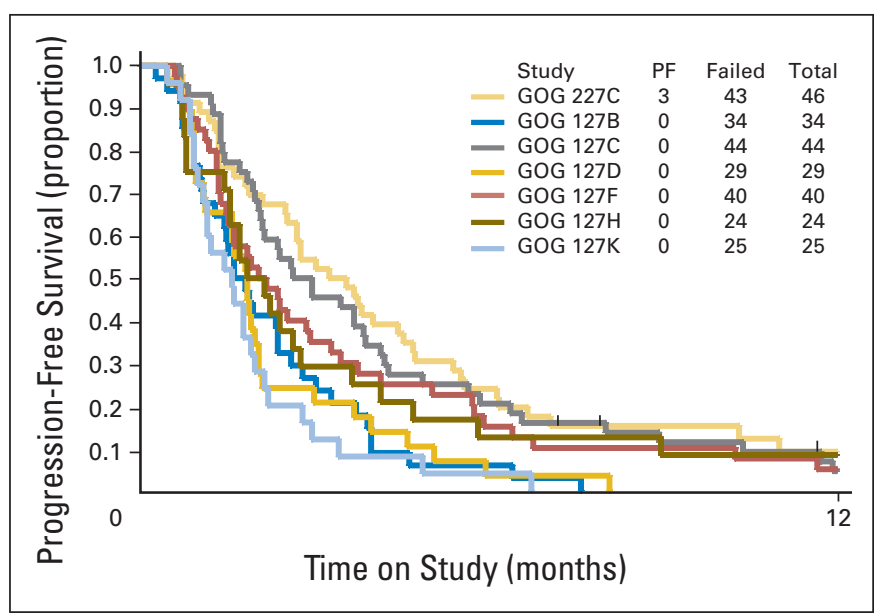

Fig 2. Nonrandomized comparison of progression-free survival (PFS) for studies listed in Table 1 and the PFS from Gynecologic Oncology Group Protocol 227-C (current study) with bevacizumab (light yellow). PF, progression free. 


\begin{tabular}{|c|c|c|c|c|}
\hline Variables in Model* & Score $\chi^{2}$ & $-2 \mathrm{LL} \dagger$ & HR Estimateł & Wald $P$ \\
\hline \multicolumn{5}{|l|}{ Progression-free survival } \\
\hline None & - & 256.233 & - & - \\
\hline Race & 4.04 & 253.345 & 2.83 & .054 \\
\hline PS & 3.49 & 252.758 & 1.84 & .065 \\
\hline Age & 3.37 & 252.822 & $-3.2 \%$ & .069 \\
\hline PRCT & 0.29 & 255.938 & 1.21 & .593 \\
\hline PRRT & 0.24 & 256.006 & 1.23 & .626 \\
\hline Age, PS & 6.82 & 249.361 & $-3.2 \%, 1.84$ & $.069, .066$ \\
\hline Race, PS & 6.39 & 250.913 & $2.28,1.70$ & $.137, .121$ \\
\hline Race, age & 5.68 & 251.610 & $2.00,-2.4 \%$ & $.244, .192$ \\
\hline Race, PS, age & 8.24 & 248.901 & $1.54,1.75,-2.7 \%$ & $.485, .102, .160$ \\
\hline \multicolumn{5}{|l|}{ Overall survival } \\
\hline None & - & 224.054 & - & - \\
\hline PS & 5.56 & 218.591 & 2.21 & .022 \\
\hline Race & 3.43 & 221.532 & 2.61 & .075 \\
\hline PRCT & 3.15 & 221.248 & 0.52 & .081 \\
\hline Age & 0.65 & 223.399 & $-1.5 \%$ & .421 \\
\hline PRRT & 0.27 & 223.797 & 1.25 & .605 \\
\hline PS, race & 7.92 & 217.060 & $2.07,2.09$ & $.037, .178$ \\
\hline PRCT, PS & 7.56 & 216.845 & $0.60,2.06$ & $.174, .038$ \\
\hline $\mathrm{PRCT}$, race & 7.51 & 217.656 & $0.45,3.33$ & $.040, .031$ \\
\hline PRCT, PS, race & 10.69 & 214.436 & $0.52,1.88,2.66$ & $.095, .076, .088$ \\
\hline \multicolumn{5}{|c|}{$\begin{array}{l}\text { NOTE. Three of the four African Americans had a PS of } 1 v 0 \text {; however, all received only one prior chemotherapy regimen. The mean age of African Americans } \\
\text { was } 35 \text { years compared with a mean age of } 48 \text { years in all other races. } \\
\text { Abbreviations: HR, hazard ratio; PS, performance status; PRCT, prior chemotherapy; PRRT, prior radiation therapy. } \\
\text { "Models that include African American cofactors are indicated by the word race. } \\
\dagger-2 \times \text { the logarithm of the likelihood function. } 24 a \\
\text { fHazard ratios are for African Americans } v \text { all other races, for having performance status } 1 \text { or } 2 v 0 \text {, for the percent change in hazard for each yearly increase in } \\
\text { age, for having one } v \text { two prior chemotherapy regimens, and for having } v \text { not having prior radiation. }\end{array}$} \\
\hline
\end{tabular}

disease (stage IVB) or recurrent lesions not amenable to salvage surgery or radiation are treated with current systemic cisplatin combination regimens, the median survival is only 9 to 10 months. ${ }^{4,6,7}$ To date, no targeted or biologic agents have shown activity in the management of patients with advanced or recurrent cervical carcinoma. Classes of agents with potential activity include epidermal growth factor receptor active agents, therapeutic human papillomavirus vaccines, oncolytic viruses, and antiangiogenesis compounds.

Although angiogenesis is clearly related to cervical cancer development and tumor progression, the tumor shrinkage resulting from cytotoxic therapy (radiation and or chemotherapy) seems to be related to an increase in mature/functional vascularity, thereby improving tumor oxygenation and chemotherapy delivery and facilitating apoptosis. To the contrary, we hypothesize that phenotypically distinct, disorganized, and leaky vascular networks, as measured by CD105 immunostaining, inefficiently deliver oxygen and chemotherapy to the tumor site and may also be markers of poor prognosis for yet unknown reasons. ${ }^{25}$ The current study was designed to test the therapeutic benefit of single-agent bevacizumab, an antiangiogenesis compound, and also to prospectively evaluate the role of angiogenesis tissue markers in predicting response; however, difficulty in collecting tumor specimens from recurrent lesions precluded this analysis. Nonetheless, assuming development of more feasible methods, discovery of predictive markers of outcomes to antiangiogenic therapy is an important translational objective in future clinical trials for cervical cancer.
When compared with a database of cytotoxic single-agent compounds studied by the GOG in the setting of treatment failure with one prior regimen for metastatic cervical cancer (Table 1), bevacizumab showed remarkable activity in the present study, with a response rate of $11 \%$ and $24 \%$ of patients remaining without progression after 6 months on protocol. This level of activity in the current report justifies a phase III trial of bevacizumab in advanced and recurrent cervical cancer.

The present study did not identify any new toxicities or an increased frequency of currently reported toxicities of bevacizumab. Bevacizumab has an extensive safety profile even among patients with prior radiation, as in the current report. ${ }^{26}$

In an attempt to identify factors predictive of outcome after treatment with bevacizumab, in the setting of recurrent cervical cancer, that could be studied prospectively in larger prospective trials, exploratory hypothesis-generating analyses were performed. These analyses suggested an increased risk of progression (or death) for those who are African American, young, and have poor performance status. This is consistent with other GOG cervical cancer trials both in the primary and the recurrent setting. ${ }^{9,27}$ The explanation for the prognostic significance of these factors is unclear, and models have been constructed using these parameters from prior phase III GOG trials that predict the likelihood of not responding to existing cytotoxic therapies, ${ }^{9}$ making clinical trials investigating novel targeted agents, such as the current study, critical to improving outcomes among these high-risk patients. 


\section{AUTHORS' DISCLOSURES OF POTENTIAL CONFLICTS} OF INTEREST

Although all authors completed the disclosure declaration, the following author(s) indicated a financial or other interest that is relevant to the subject matter under consideration in this article. Certain relationships marked with a "U" are those for which no compensation was received; those relationships marked with a " $C$ " were compensated. For a detailed description of the disclosure categories, or for more information about ASCO's conflict of interest policy, please refer to the Author Disclosure Declaration and the Disclosures of Potential Conflicts of Interest section in Information for Contributors.

Employment or Leadership Position: None Consultant or Advisory Role: None Stock Ownership: Lynda D. Roman, Genentech Inc Honoraria: Robert A. Burger, Genentech Inc Research Funding: Lynda
D. Roman, Genentech Inc Expert Testimony: Lynda D. Roman, Kaiser Permanente (C) Other Remuneration: None

\section{AUTHOR CONTRIBUTIONS}

Conception and design: Bradley J. Monk, Michael W. Sill,

Robert A. Burger

Administrative support: Michael W. Sill

Provision of study materials or patients: Bradley J. Monk, Robert A. Burger, Heidi J. Gray, Thomas E. Buekers, Lynda D. Roman

Collection and assembly of data: Bradley J. Monk, Robert A. Burger Data analysis and interpretation: Bradley J. Monk, Michael W. Sill Manuscript writing: Bradley J. Monk, Michael W. Sill, Robert A. Burger Final approval of manuscript: Bradley J. Monk, Michael W. Sill, Robert A. Burger, Heidi J. Gray, Thomas E. Buekers, Lynda D. Roman

\section{REFERENCES}

1. Parkin DM, Bray F, Ferlay J, et al: Global cancer statistics, 2002. CA Cancer J Clin 55:74-108, 2005

2. American Cancer Society: Cancer facts and figures 2007. http://www.cancer.org/downloads/STT/ CAFF2007PWSecured.pdf

3. Monk BJ, Herzog TJ: The evolution of costeffective screening and prevention of cervical carcinoma: Implications of the 2006 consensus guidelines and human papillomavirus vaccination. Am J Obstet Gynecol 197:337-339, 2007

4. Monk BJ, Tewari KSL: Chapter 3: Invasive cervical cancer, in DiSaia PJ, Creasman WT (eds): Clinical Gynecologic Oncology (ed 7). New York, NY, Mosby, Inc, 2007, pp 55-124

5. Monk BJ, Tewari KS, Koh WJ: Multimodality therapy for locally advanced cervical carcinoma: State of the art and future directions. J Clin Oncol 25:2952-2965, 2007

6. Tewari KS, Monk BJ: Gynecologic oncology group trials of chemotherapy for metastatic and recurrent cervical cancer. Curr Oncol Rep 7:419-434, 2005

7. Long HJ III, Bundy BN, Grendys EC, et al: Randomized phase III trial of cisplatin with or without topotecan in carcinoma of the uterine cervix: A Gynecologic Oncology Group study. J Clin Oncol 23:4626-4633, 2005

8. Monk BJ, Huang HQ, Cella D, et al: Quality of life outcomes from a randomized phase III trial of cisplatin with or without topotecan in advanced carcinoma of the cervix: A Gynecologic Oncology Group study. J Clin Oncol 23:4617-4625, 2005

9. Moore DH, Tian C, Monk BJ, et al: Factors predictive of response to cisplatin-based chemotherapy in stage IVB persistent or recurrent cervical carcinoma: A multivariate analysis of three Gynecologic Oncology Group trials. J Clin Oncol 25:282s, 2007 (suppl; abstr 5534)
10. Rose PG, Blessing JA, Gershenson DM, et al: Paclitaxel and cisplatin as first-line therapy in recurrent squamous cell carcinoma of the cervix: A Gynecologic Oncology Group study. J Clin Oncol 17: 2676-2680, 1999

11. Rasila KK, Burger RA, Smith $H$, et al: Angiogenesis in gynecological oncology-mechanism of tumor progression and therapeutic targets. Int $\mathrm{J}$ Gynecol Cancer 15:710-726, 2005

12. Gaffney DK, Haslam D, Tsodikov A, et al: Epidermal growth factor receptor (EGFR) and vascular endothelial growth factor (VEGF) negatively effect overall survival in carcinoma of the cervix treated with radiotherapy. Int J Radiat Oncol Biol Phys 56:922-928, 2003

13. Shih T, Lindley C: Bevacizumab: An angiogenesis inhibitor for the treatment of solid malignancies. Clin Ther 28:1779-1802, 2006

14. Therasse P, Arbuck SG, Eisenhauer EA, et al: New guidelines to evaluate the response to treatment in solid tumors: European Organization for Research and Treatment of Cancer, National Cancer Institute of the United States, National Cancer Institute of Canada. J Natl Cancer Inst 92:205-216, 2000

15. Pentecost MJ, Criqui MH, Dorros G, et al: Guidelines for peripheral percutaneous transluminal angioplasty of the abdominal aorta and lower extremity vessels: A statement for health professionals from a special writing group of the Councils on Cardiovascular Radiology, Arteriosclerosis, CardioThoracic and Vascular Surgery, Clinical Cardiology, and Epidemiology and Prevention, the American Heart Association. Circulation 89:511-531, 1994

16. National Cancer Institute: Common Toxicity Criteria v2.0. http://ctep.cancer.gov/reporting/ctc.html

17. Look KY, Blessing JA, Nelson BE, et al: $A$ phase II trial of isotretinoin and alpha interferon in patients with recurrent squamous cell carcinoma of the cervix: A Gynecologic Oncology Group study. Am J Clin Oncol 21:591-594, 1998

18. Mannel RS, Blessing JA, Boike G: Cisplatin and pentoxifylline in advanced or recurrent squa- mous cell carcinoma of the cervix: A Gynecologic Oncology Group study. Gynecol Oncol 79:64-66, 2000

19. Rose PG, Blessing JA, Arseneau J: Phase II evaluation of altretamine for advanced and recurrent squamous cell carcinoma of the cervix: A Gynecologic Oncology Group study. Gynecol Oncol 62:100102, 1996

20. Bookman MA, Blessing JA, Hanjani $P$, et al: Topotecan in squamous cell carcinoma of the cervix: A phase II Gynecologic Oncology Group study. Gynecol Oncol 77:446-449, 2000

21. Rose PG, Blessing JA, Van Le $L$, et al: Prolonged oral etoposide in recurrent or advanced squamous cell carcinoma of the cervix: A Gynecologic Oncology Group study. Gynecol Oncol 70:263-266, 1998

22. Schilder R, Blessing JA, Morgan $M$, et al: Evaluation of gemcitabine in patients with squamous cell carcinoma of the cervix: A phase II study of the Gynecologic Oncology Group. Gynecol Oncol 76:204-207, 2000

23. Chen TT, Ng TH: Optimal flexible designs in phase II clinical trials. Stat Med 17:2301-2312, 1998

24. Clopper CJ, Pearson ES: The use of confidence or fiducial limits illustrated in the case of the binomial. Biometrika 26:404-413, 1934

24a. Collett D: Modeling Survival Data in Medical Research. New York, NY, Chapman and Hall, 1994, p 75

25. Randall LM, Monk BJ, Darcy KM, et al: GOG markers of angiogenesis in early-stage cervical cancer: A Gynecologic Oncology Group study. Gynecol Oncol 108:S22, 2008 (suppl)

26. Genentech, Inc: Avastin full prescribing information: Warnings. http://www.gene.com/gene/products/ information/oncology/avastin/insert.jsp

27. Monk BJ, Tian C, Rose PG, et al: Which clinical/pathologic factors matter in the era of chemoradiation as treatment for locally advanced cervical carcinoma? Analysis of two Gynecologic Oncology Group (GOG) trials. Gynecol Oncol 105: 427-433, 2007 